
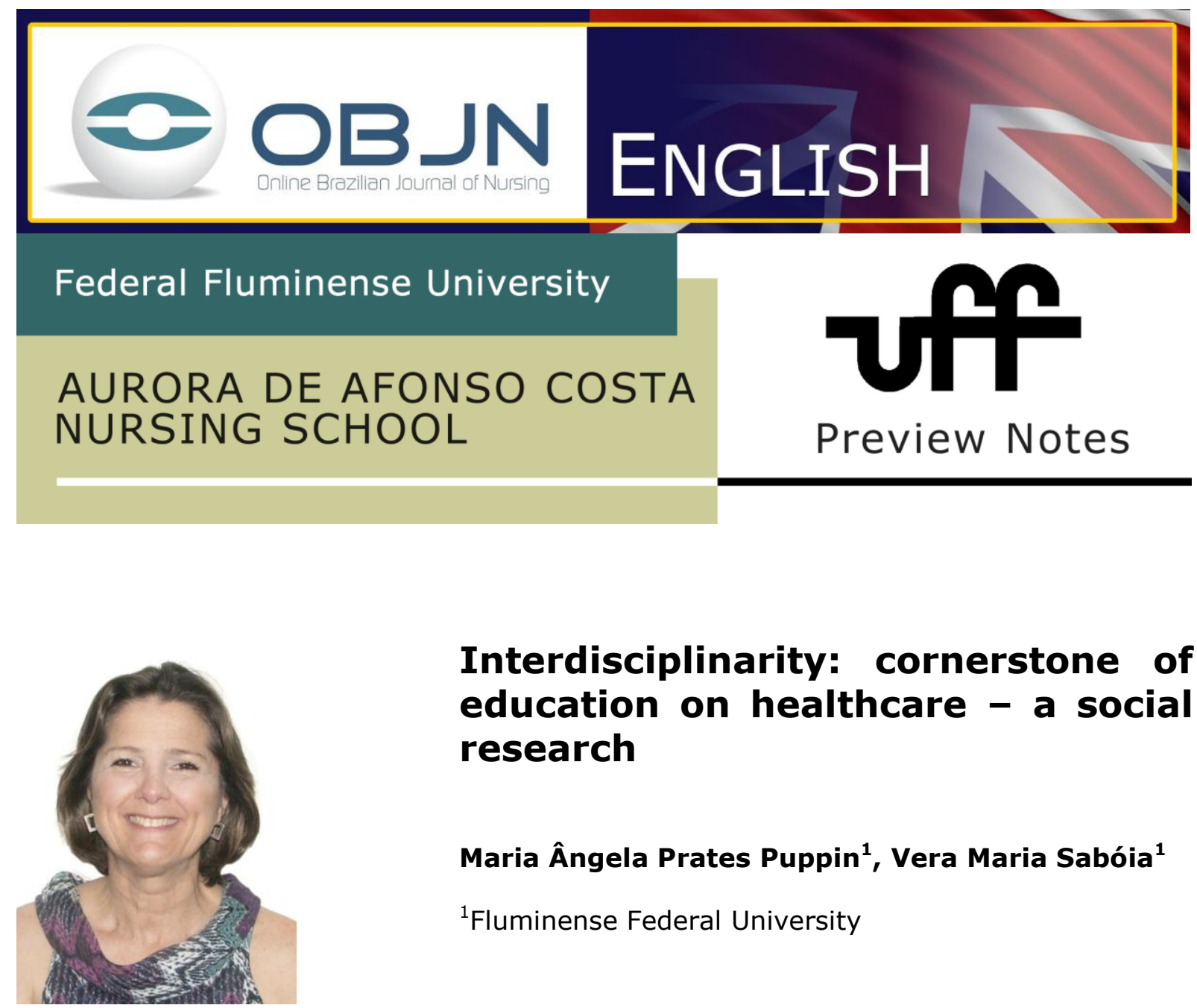

\title{
Interdisciplinarity: cornerstone of education on healthcare - a social research
}

\author{
Maria Ângela Prates Puppin', Vera Maria Sabóia ${ }^{1}$ \\ ${ }^{1}$ Fluminense Federal University
}

\begin{abstract}
This project addresses interdisciplinary pedagogy and its implementation in the Collective Health Nursing Residency Program, Fluminense Federal University. Some decades ago, curricular reform movements in health mainly took place in Latin America, with the aim of overcoming the prevalent and traditional guidelines, as supported by specialisms and by individualized and content-focused teaching practice. The study objectives are: to describe the development of care provided by resident nurses, in terms of interdisciplinarity; to examine whether interdisciplinarity has been encouraged during their training and; to discuss with teachers and residents the construction and implementation of interdisciplinarity in professional practice. Method: This is a qualitative research project in which we adopted a descriptive approach that is set in the Service Training Units. The instruments of data collection are semi-structured interviews and free participative observation. Thematic analysis will be used to construct analytical categories, contextualizing the problem in the light of the work of scholars such as Minayo, Japiassú, Ceccim and Fazenda.
\end{abstract}

Keywords: Education; Interdisciplinary Communication; Patient Care Team 


\section{THE PROBLEM AND ITS SIGNIFICANCE}

Since its creation in the early Twentieth Century, as well as its precursors, Brazilian universities have been characterized by a lack of educational principles that have stimulated the development of critical and transforming individuals. The purely technical and operational training used in a hegemonic way with regard to the formation of health professionals, without considering the pedagogical aspects required for such activity, has not proven to be sufficient to meet the changes in the world of work and in response to changing education policies. In order to introduce interdisciplinarity at university level as a dynamic principle, it is essential that we develop an attitude which recognises personal limitations and openness as a means of building knowledge and practices collectively. The performance of the teaching profession in introducing more critical teaching practices to allow for the formation of the academic community is essential, without neglecting the need for care for the demands of the population that is involved in the learning scenarios associated with healthcare ${ }^{(1)}$. Considering the complexity of the subject of health, education and care should be practiced "naturally" in an interdisciplinary fashion, setting up the fundamental assumptions for the work of professionals in a healthcare team.

Interdisciplinary pedagogy emerged and began to develop in Brazil, along with other post-critical theories, in 1993. This was in the face of the perception of difficulties with regard to implementing public health policies, both in relation to its programs, and to the training of human resources, in terms of the necessary and desired profile. To conceptualize the interdisciplinary approach we should ask the following question: How do we demand an interdisciplinary attitude on the part of professionals who have graduated without ever having had even minimal curricular experiences in this regard?

We now consider some assumptions that initially configure the map of interdisciplinary pedagogy and which may be revised or adjusted for each specific teaching and learning situation in terms of its dynamic nature: care and education (educare) in healthcare are practices which are "naturally" interdisciplinary, and thus need to be understood by all the members of the healthcare team; the complexity of healthcare demands 
interdisciplinary attention; the teaching programs in the healthcare area need to incorporate care and education as a "boundary object"; the courses in the healthcare area need to offer interdisciplinary educational experiences to help develop healthcare professionals $^{(2)}$. Interdisciplinarity rejects a unifying position, which is taken as the basis for all sciences and is kept separate from the historical and cultural processes and contexts. Rather, this proposal must comply with the contents of each field of knowledge, as well as distinguish the points that unite and cause them to differ. Interdisciplinarity also seeks to overcome scientific rationale, and proposes to institutionalize the production of knowledge in the areas of research and new curricular paradigms, through communication in terms of the process of perceiving the various disciplines ${ }^{(3)}$.

\section{GUIDING QUESTIONS}

How do resident-nurses in Public Health have interdisciplinarity experience within the Service Training Units?

Has interdisciplinarity been developed in this teaching program as a guiding principle for teamwork and integrated care?

\section{OBJECTIVES}

To analyze whether or not, in theory and in practice, interdisciplinarity is encouraged in the Collective Health Nursing Residency Program; to discuss with teachers and residentnurses the construction and implementation of the interdisciplinary vision in professional practice as developed in the service training units. 


\section{HYPHOTESES}

Considering that the healthcare field necessitates the use of interdisciplinary knowledge and practice spanning human and social sciences, it is essential that the development of theoretical knowledge and the performance of the professionals involved in this activity consider, in its proposals, the practices carried out by the population, and the concrete possibility of the elaboration of new knowledge shared between healthcare professionals and health users. This is the main idea that guides this research and is also one of its assumptions.

\section{METHOD}

This is a study that has adopted a qualitative approach, making use of an exploratory and descriptive style. The setting for the research will be the School of Nursing Aurora de Afonso Costa, Fluminense Federal University and the Service Training Units, where residents develop their theoretical and practical activities. Data collection will take place through the use of semi-structured interviews and free participant observation, after the subjects have signed an agreement and an Informed Consent Form (ICF). The research will have as its subjects, the teachers and first year resident-nurses (R1) of the Collective Health Nursing Residency Program, School of Nursing Aurora de Afonso Costa, Fluminense Federal University. After finalising the fieldwork, the data collected will be analyzed and then an approximation of results will be produced with the goal of building core categories which express the thoughts of all those who took part in the research, and which may be referred to a larger reality. As a technique for the treatment of the material collected, thematic analysis will be used. The categories derived from the testimonies of the subjects will be considered by researchers who have studied similar themes. The research project has already been submitted for consideration to the Ethics Committee in Research (CEP) of the Antonio Pedro University Hospital (HUAP-UFF). After approval, it will be presented to the research subjects and all clarifications will be given 
with regard to their participation. Afterwards these subjects will be asked to voluntarily sign the Instrument of Consent (IC), as stated in Resolution No. 196/96 of the National Health Council.

\section{REFERENCES}

1. Mourão LC; L' Abbate S. Implicações docentes nas transformações curriculares da área da saúde: uma análise sócio-histórica. Online Braz J Nurs [Serial in the internet]. 2011 [cited 2012 may 30]; 10 (3). Available from: http://www.uff.br/objnursing/index.php/nursing/article/view/400/95

2. Saupe R; Budó MLD. Pedagogia interdisciplinar: "educare" (educação e cuidado) como objeto fronteiriço em saúde. Texto \& Contexto Enferm [serial in the internet]. 2006 [cited 2011 Apr 20]; 15 (2) Available from: http://www.scielo.br/scielo.php?pid $=$ S010407072006000200018\&script $=$ sci arttext

3. Pós-modernidade, política e educação [homepage in the internet]. Siqueira HCG, Pereira MA. Interdisciplinaridade como superação da fragmentação. [cited 2005 Out 23]. Available from: http://www.angelfire.com/sk/holgonsi/interdiscip3.html

Project Data: dissertation project of the Professional Master Program in Health Education at UFF.

Advisor: Vera Sabóia

Mailing address: uffmest@gmail.com

Received: $10 / 07 / 2012$

Approved: 11/09/2012 